\title{
Extracting Leadership Competencies through Training of Orientation Assistants
}

\author{
Linda L. Mellish, Mary Beth Corbin, Karen Smith, and Hank Bowen
}

Orientation Assistants (OAs) make an immediate and long-lasting impact on an incoming class. Selection and training of those possessing specific characteristics is critical to a successful freshman orientation. A proven model is in place at our institution. A gap is present in the leadership components and measurements embedded within this training. This study will focus on Situational Leadership ${ }^{\circledR}$ training as developed by Blanchard, Zigarmi, and Zigarmi (1985) in our modules. Both quantitative and qualitative data will be presented.

\section{Introduction}

Orientation Assistants (OAs) are upper-class students selected to assist incoming students with their transition to the university. These student leaders are tasked with the responsibility of guiding small groups of wide-eyed, curious, and often anxious students who are preparing to begin their own university journey. Throughout the day-and-a-half time frame, OAs serve as guides, counselors, and mentors. As student leaders, this group has great impact on new students.

Komives, Lucas, and McMahon (2007) use the term "leader" as a person who intentionally engages with others to accomplish change, as opposed to a positional leader, who has a title such as chair, vice-president, or captain. Like the leader who engages to accomplish change, the purpose of leadership is to accomplish or change something (Komives et al, 2007).

Two models of leadership are utilized in the development of the selection and training continuum for the OAs at our institution. One key element of success for integration of leadership competencies in this training model is the understanding of the Relational Leadership Model by the orientation staff and students. Relational Leadership consists of five components including being purposeful, inclusive,

Linda L. Mellish (mellishl@ecu.edu) is the Associate Director, Research and Assessment In the Office of Student Transitions and Campus Living at East Carolina University

Mary Beth Corbin is the Executive Director of Student Transitions and First-Year Center at East Carolina University

Karen Smith is the Associate Director of the Office of Student Transitions and First Year Center at East Carolina University

Hank Bowen is the Coordinator of First Year Programs in the Office of Student Transitions and First Year Center at East Carolina University 
empowering, ethical, and process-oriented (Komives, Lucas, \& McMahon, 2007). Embedded in each of these five components are knowing (knowledge and understanding), being (attitudes), and doing (skills; Komives et al., 2007). The second key element is recognition of the leadership style that is well aligned with the maturity or developmental level of the group of participating students (Blanchard, Zigarmi, \& Zigarmi, 1985).

In order for the OAs to have the desired impact on incoming students, they must first understand themselves and the new knowledge required for the position and must also be aware of and appreciate the differences between self and others. Finally, OAs must develop skills for listening, group building, interpersonal skills and effective civil discourse. Orientation Assistant training incorporates both the Relational Leadership and the Situational Leadership Models as they develop a better understanding of knowing-being-doing in their work with others. Qualitative data was collected and analyzed for self-assessed pre and post training effect of leadership competency development.

\section{Selection and Training}

Given that Orientation Assistants (OAs) make an immediate and long-lasting impact on an incoming class, selection and training of these student leaders is critical to a successful freshman orientation. We asked ourselves, "Are we doing the best training for our OAs, preparing them for their own success in this position?" After analyzing our prior iterations, a gap was observed in the assessment of leadership components embedded within the training. Again, we asked ourselves, "Is our training developing student leaders? Providing enough support and challenge for their development? Do they realize they are developing skills as student leaders?"

\section{Our Rigorous Selection Process}

An alteration in leadership competencies is an expected outcome of orientation assistant training. As a result of successfully navigating the selection process and completing the training and orientation sessions, the OAs would be able to articulate the training impact on their leadership competencies.

Our orientation assistants are selected from a highly competitive applicant pool. Of the 75 applicants desiring to obtain the standing of orientation assistant in 2013, 25 student leaders were selected. A stringent application process is followed. An application is submitted, which consists of three essay questions and two reference forms. Applicants complete a group interview, which is used to observe their skills such as communication, group dynamics, leadership potential, understanding of first-year student needs, responses to scenarios, and more. The final step is an individual interview with the associate director and coordinator, where a structured interview is performed, and a rubric is completed for each applicant. Individual letters are sent to each applicant informing them of their status. Given the results of our orientation surveys, parents and students are 
extremely pleased with the skills and knowledge our OAs present during sessions. We are selecting highly qualified and highly committed individuals as OAs. Thirtytwo percent of these student leaders were male, slightly lower than our institution's population. The majority ( $80 \%$ ) were in-state students and $20 \%$ were out-of-state; this is comparable to our institution's population. Thirty-two percent self-identified as minority students. The orientation assistants represented a wide variety of majors.

We wanted to do more for them than providing the orientation opportunity. We wanted to assist in developing them as student leaders. Blanchard et al., (1985) present leadership styles which are most applicable given the variation in the level of maturity of the OAs; our 2013 OAs covered the entire academic classification schema. Eight were seniors, twelve were juniors, three were sophomores, and two were freshmen, according to academic standing. As incoming students are assigned randomly to an OA for their orientation experience, it is up to the OA to quickly adapt to the new population every two days. This is essential for maximizing information dissemination and building a quick relationship between the two entities for that exchange. Situational Leadership ${ }^{\circledR}$ training follows this premise: if the competence of a particular individual is low, but his or her commitment to the task is high, one would model a more directive style of leadership as that individual grows and develops. If his or her competence and commitment to the task are both high, delegating would be a more appropriate style of leadership to further development. We began to identify our student leaders' levels of maturity and expressed leadership competencies through their responses during the selection process as well as their pre training survey response. Since our OAs all exhibited a high commitment to being an OA, we scaffolded the knowledge in the training content to build their competency level depending on where they were: "some" leadership competence to "high" leadership competence. At the completion of the training, we provided the post training survey to assess their level and leadership knowledge gained.

\section{Results}

A pre-post test survey instrument was developed and used to assess self-knowledge and goal setting for the OAs' training experience. Twenty-three of the twenty-five OAs participated. The pre survey consisted of the following questions:

1. What are your expectations of the Orientation Assistant Training Week?

2. What are three expectations for your own Personal Growth by participating in this week of training?

3. What are three expectations for your own Leadership Development by participating in this week of training?

The post survey was as follows:

1. Were your expectations of the Orientation Assistant Training Week met?

2. What three expectations for your own Personal Growth did you achieve by participating in last week's training?

3. Did that differ from what you expected to achieve in terms of Personal Growth? 
The qualitative analysis that followed revealed four categories pertaining to leadership that mattered to the OAs: they wanted to be knowledgeable with detailed information, good role models for the incoming students and one another, communicate effectively, and exhibit confidence. Responses were broken down by gender and are depicted by level of importance below for the pre training survey:

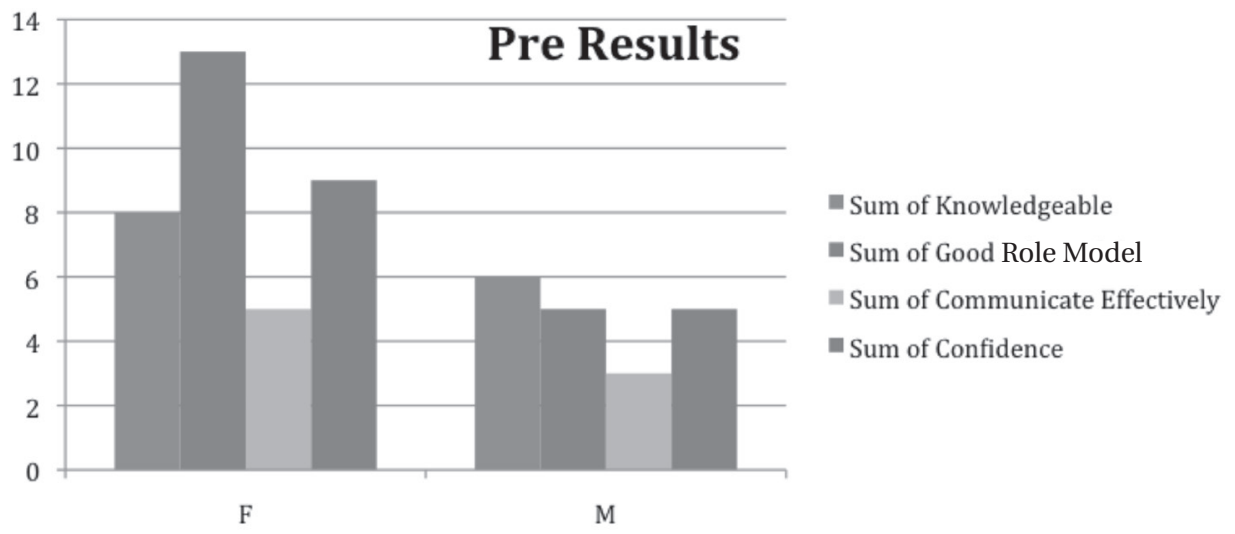

The post training survey revealed a shift in categorical knowledge. This was a surprise to the OAs. Here are the post training results:

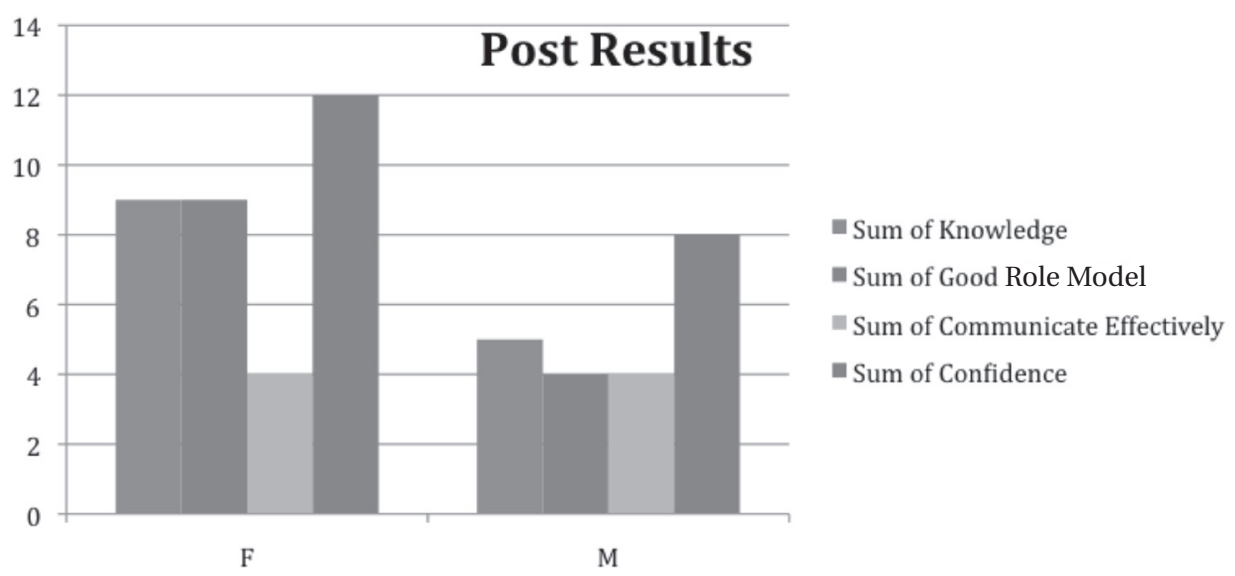

The increase in confidence far exceeded the pre training predictions of the OAs, particularly for the female OAs. This increase may be explained by a number of skills achieved during training. The student leaders are given a tremendous amount of information to learn, they are taught through a variety of techniques, including role playing, scenarios, and games. Perhaps their expressed increase in confidence is tied to their increase in knowledge and exposure to a variety of 
possible scenarios, which addresses an increased level of competence. This gain in confidence is certainly evident in their daily interaction with the incoming students and their ability to respond to the different group of students every two days.

\section{Theoretical and Practical Implications for Student Affairs}

Committed investigation and attention to orientation programming has been conducted for over 20 years (Ward-Roof, J.A., 2010). Throughout this time, best practices have been shared through rigorous research, resulting in the design of pertinent orientation programs. Student Affairs has an impact on each and every student attending a university. The dissemination of the cultural capital needed by the students, particularly those in the freshman class, has to be specific, intentional, applicable, useful, and timely. The OAs are the frontline for this distribution; therefore, their selection and training needs to reflect the most useful methods, building their leadership skills and competence. It is by drawing on what we know through Student Affairs research that orientation assistants will be the student leaders we have prepared them to be.

\section{References}

Blanchard, K., Zigarmi, P., \& Zigarmi, D., (1985). Leadership and the one minute manager: Increasing effectiveness through situational leadership. New York, NY: William Morrow and Company, Inc.

Komives, S., Lucas, N., \& McMahon, T. (2007). Exploring leadership (2nd ed.). San Francisco, CA: Jossey-Bass.

Ward-Roof, J. S. (2010). Designing successful transitions: A guide for orienting students to college (Monograph No. 13, 3rd ed.). Columbia, SC: University of South Carolina, National Resource Center for The First-year Experience and Students in Transition. 